\title{
Right Bochdalek congenital diaphragmatic hernia: a tertiary center's experience over 13 years
}

\author{
Alshaima Alghamdi* (D) and Enaam Raboe
}

\begin{abstract}
Background: Right Bochdalek congenital diaphragmatic hernia (RB-CDH) is far less common than left Bochdalek congenital diaphragmatic hernia, accounting for only $13 \%$ of cases. There are limited published data on the outcomes and survival rate of RB-CDH.

We aimed at investigating the clinical characteristics and analyzing the risk factors of survival in neonates with RB$\mathrm{CDH}$ treated in our center over a period of 13 years.

Results: Fifteen infants with RB-CDH were identified. Most of the patients were full term (74\%). The mean birth weight was $2.90 \pm 0.72 \mathrm{~kg}$. The ratio of male to female was 2:1. The mean APGAR score at 1 min was 5.31 2.34 , and $7.30 \pm 1.59$ at $5 \mathrm{~min}$. Ten patients (67\%) were imaged by antenatal ultrasound. Eleven patients (73.33\%) survived to go for surgical repair. The hernia sac was found in 5 patients (45\%). Most hernial defects were closed in a primary fashion. The mean age at the operative repair was $8.11 \pm 9.90$ days. The average NICU stay for all patients was $40.47 \pm$ 50.38 days. The mean follow-up period was $20.45 \pm 9.34$ months. Three patients had postoperative complications. The total survival rate in neonates with RB-CDH was 9/15 (60\%). Nine out of 11 (82\%) neonates survived after surgical repair. Four patients (27\%) died before surgical repair. Ventilation-related bilateral pneumothorax was a contributing cause of death in three patients. Birth weight was found lower in the non-survivor's group $(P<0.05)$. Moreover, the degree of pulmonary hypertension was more severe among non-survivors. No statistical significance was observed between other variables and mortality.

Conclusion: We found that low birth weight and the presence of severe PHTN were risk factors for mortality in neonates with RB-CDH. These results are in line with previous studies on prognostic factors in $\mathrm{CDH}$. Ventilatorrelated pneumothorax appears to be a significant contributing cause of death. Long-term follow-up studies of infants born with RB-CDH are needed as small number of cases limits large-volume RB-CDH studies.
\end{abstract}

Keywords: Right diaphragmatic hernia, Congenital diaphragmatic hernia, Bochdalek diaphragmatic hernia

\section{Background}

Congenital diaphragmatic hernia $(\mathrm{CDH})$ represents a rare developmental defect, with an estimated prevalence of 2-4 per 10,000 live births in the USA and Europe [1, 2]. While a growing proportion of cases are diagnosed prenatally, some are diagnosed at birth due to immediate respiratory distress.

\footnotetext{
* Correspondence: Shaima.under.D@gmail.com

King Fahd Armed Forces Hospital, Jeddah, Saudi Arabia
}

The diaphragm develops from the fusion of four embryonic components [3]. The posterolateral (Bochdalek) diaphragmatic hernia accounts for $90 \%$ of all diaphragmatic hernia cases. The right Bochdaleck congenital diaphragmatic hernia (RB-CDH) is less common than the left Bochdaleck congenital diaphragmatic hernia (LB$\mathrm{CDH})(13 \%$ vs $85 \%$, respectively) [4].

Pulmonary hypertension (PHTN) occurs in up to $75 \%$ of infants with $\mathrm{CDH}$ [5]. The severity of pulmonary 
hypoplasia and hypertension are the major determinants of overall survival in those patients [6,7].

The mortality of $\mathrm{CDH}$ neonates remains high despite neonatal intensive care improvements [8]. The reported 24-h mortality ranges between $21-31 \%$, whereas the 1 year mortality can be as high as $46 \%$ [9]. There are limited published literature on the outcomes and associations of RB-CDH.

\section{Aim}

Our study aimed at investigating the clinical characteristics and analyzing the risk factors of survival in neonates with RB-CDH treated in our center over a period of 13 years.

\section{Methods}

We conducted a retrospective study of all infants with RB-CDH treated at our tertiary care hospital between January 2005 and January 2018. The inclusion criterion was a diagnosis of RB-CDH. Infants who had diaphragmatic eventration were excluded.

The diagnosis of $\mathrm{RB}-\mathrm{CDH}$ was made by prenatal ultrasonographic scans, plain chest radiography films, or contrast-enhanced computerized tomography in doubtful cases. Cardiac malformations were diagnosed using two-dimensional (2D) echocardiography.

The following variables were assessed: gestational age, mode of delivery, Apgar score at 1 and $5 \mathrm{~min}$, birth weight, associated anomalies, duration of mechanical ventilation, and the severity of pulmonary hypertension, in addition to the surgical approach, timing of repair, need for a surgical patch, postoperative complications, and recurrence of hernia.

Data are presented as an absolute number with a percentage or mean \pm standard deviation. A univariate analysis was performed to describe demographic and perioperative data. A comparison between two groups (group $\mathrm{A}=$ survivors/group $\mathrm{B}=$ non-survivors) was performed using a Student's $t$ test for continuous variables and Fisher's exact test for categorical variables. A $P$ value
$<.05$ was defined as significant. The statistical analysis was performed using the statistical software (IBM SPSS Statistics for Windows, Version 22.0., IBM Corp, Armonk, NY, USA).

\section{Results}

We identified 15 infants with RB-CDH during the study period (Fig. 1). Most of the patients were full term (74\%). The mean birth weight was $2.90 \pm 0.72 \mathrm{~kg}$. There were 10 males $(67 \%)$ and 5 females $(33 \%)$ with a male to female ratio of 2:1. Seven newborns (47\%) were delivered by cesarean section, and eight were delivered vaginally (53\%). The mean APGAR score was $5.31 \pm 2.34$, and $7.30 \pm 1.59$ at $1 \mathrm{~min}$ and $5 \mathrm{~min}$, respectively.

All patients were diagnosed from prenatal ultrasound and/or radiological imaging after birth, with the clinical signs of tachypnea, apnea, bradycardia, desaturation to Spo 2 less than $90 \%$ and scaphoid abdomen. Ten patients (67\%) were diagnosed by antenatal ultrasound. RB-CDH was found only in 6 fetuses (40\%), 2 fetuses (13\%) had signs of hydrops (pleural effusion, pericardial effusion, and ascites), and 2 (13\%) had only polyhydramnios. All newborns were diagnosed by chest X-ray, but four of them needed chest CT scans to confirm the diagnosis.

More than quarters (27\%) of the parents were consanguineous. Nine mothers did not have any medical illness (60\%), whereas four (27\%) had DM, VSD, or hypothyroidism. Two mothers (13\%) had multiple abortions. Eleven patients survived to undergo repair with laparotomy. One patient needed an additional right thoracotomy for hepatopulmonary fusion. The liver was the most frequently herniated organ-found in $10 \mathrm{pa}$ tients (91\%) - followed by small bowel (82\%) and large bowel (36\%). The hernial sac was found in five patients (45\%).

Most hernial defects were closed primarily using either polypropylene, silk, or polyester sutures. Polytetrafluoroethylene (PTFE) mesh was used in one patient with a large defect and transversus abdominis muscle flap was fashioned to close the defect in another patient. The

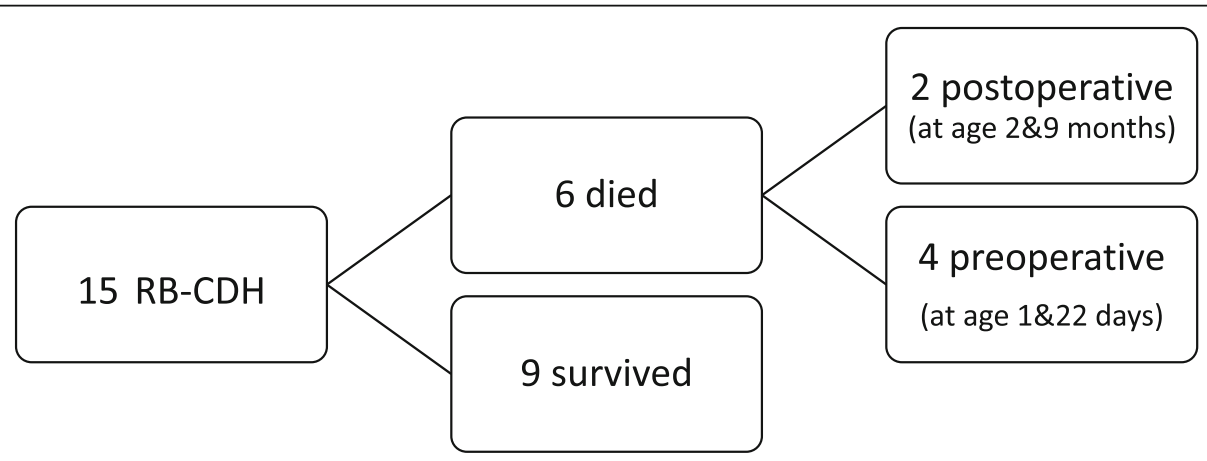

Fig. 1 Flow diagram of infants with $\mathrm{RB}-\mathrm{CDH}$ 
mean age at the operative repair was $8.11 \pm 9.90$ days. The average NICU stay for all patients was $40.47 \pm 50.38$ days.

The mean follow-up period was $20.45 \pm 9.34$ months. Three patients had postoperative complications, two had an incisional hernia, and one had GERD. One patient had recurrences twice, which mandated mesh repair at the age of 6 months. The total survival rate in neonates with RB-CDH was 9/15 (60\%), and two (18\%) died postoperatively from severe persistent pulmonary hypertension of the newborn (PPHN) and cardiac complications at the age of 2 months and 9 months, respectively. Four patients (27\%) died early after birth (before the surgical repair), three of them died on the first day of life, and one died at the age of 22 days. Ventilation-related bilateral pneumothorax was a contributing cause of death in three patients. Nine out of eleven (82\%) neonates survived after surgical repair.

When a comparison was made among the survivors ( $n$ $=9$ ) and non-survivors $(n=6)$ (Table 1$)$, birth weight was found lower in non-survivors, which was statistically significant $(P<0.05)$. Moreover, the degree of pulmonary hypertension was more severe among non-survivors. There was no statistically significant difference in gestational age, Apgar score, and cardiac malformations between RB-CDH survivors 9/15 (60\%) and non-survivors $6 / 15$ (40\%). The details of cardiac abnormalities are shown in Table 2. Though most of the dead patients required HFOV (83.33\%), the result was not statistically significant compared to only $44.44 \%$ of the survivors. Two of the survivors had associated non-cardiac anomalies (undescended testicle, grade1 hydronephrosis, and hydrocephalus). It was noticed that the average number of days of mechanical ventilation (HFOV and conventional ventilation) in the survivor group was $14.33 \pm$ 9.77days.

\section{Discussion}

$\mathrm{CDH}$ has been recognized as a syndrome, including diaphragmatic defects, pulmonary hypoplasia, and pulmonary hypertension $[10,11]$. Some authors have observed a female predominance for a Bochdalek hernia; however, others have observed a male predominance [12]. In our study, also male preponderance was noted in RB-CDH.

Neonates with $\mathrm{CDH}$ are at risk for prematurity and low birth weight (LBW), which predisposes them to increased mortality $[13,14]$. Grover et al. reported that the mortality rate of preterm neonates with $\mathrm{CDH}(<34$ weeks or birth weight $<2000 \mathrm{~g}$ ) was $50 \%$, compared to $27 \%$ mortality rate for neonates $>34$ weeks [15]. In this study, 5 of our patients $(33 \%)$ were preterm ( $<37$ weeks), 3 of them $(60 \%)$ died. We found no significant difference in mean gestational age at birth between survivors and non-survivors.

$\mathrm{CDH}$ is usually diagnosed immediately after birth with signs of respiratory distress and mediastinal shift on chest plain film [16]. All patients had respiratory distress features at birth, which is related to uncorrectable pulmonary hypoplasia and potentially reversible pulmonary hypertension [16].

A low Apgar score is usually associated with severe asphyxia and is a major independent predictor of mortality rate. However, our results suggest that the non-survivor group did not have statistically significant lower Apgar scores compared to the survivor group.

Table 1 Comparison between survivors and non survivors of right-sided congenital diaphragmatic hernia patients

\begin{tabular}{|c|c|c|c|}
\hline & Survivors $(9 / 15)$ & Non-survivors $(6 / 15)$ & $P$ value \\
\hline Gestational age (weeks) & $\begin{array}{l}\text {-Mean } 38.56 \pm 2.19 \\
7 \text { full term }(77.78 \%) \\
2 \text { preterm }(22.22 \%)\end{array}$ & $\begin{array}{l}- \text { Mean } 35.67 \pm 4.03 \\
3 \text { full term }(50 \%) \\
3 \text { preterm }(50 \%)\end{array}$ & .093 \\
\hline Birth weight (kg) & -Mean $3.32 \pm 0.45 \mathrm{~kg}$ & -Mean $2.35 \pm 0.78$ kg & .008 \\
\hline \multirow[t]{2}{*}{ Apgar score (out of 10) } & -Mean at 1 min: 5.67 \pm 2.79 & -Mean at 1 min: $5 \pm 1.55$ & .604 \\
\hline & -Mean at 5 min: $7.33 \pm 1.50$ & -Mean at 5 min: $7 \pm 1.55$ & .683 \\
\hline Cardiac malformations & $\begin{array}{l}-5 \text { newborns }(55.56 \%): \\
4 \text { PDA } \\
3 \text { ASD/PFO } \\
1 \text { VSD } \\
1 \text { pulmonary artery stenosis }\end{array}$ & $\begin{array}{l}-5 \text { newborns (83.33\%): } \\
4 \text { ASD/PFO } \\
3 \text { PDA } \\
3 \text { right side aortic arch } \\
1 \text { VSD } \\
1 \text { pulmonary artery stenosis } \\
1 \text { double outlet right ventricle }\end{array}$ & .580 \\
\hline $\begin{array}{l}\text { Pulmonary hypertension } \\
\text { (estimated from echocardiography } \\
\text { done at first week of life) }\end{array}$ & $\begin{array}{l}-6 \text { newborns (66\%) had mild PHTN. } \\
-3 \text { newborns (33\%) had moderate to severe PHTN. }\end{array}$ & -All (100\%) had signs of severe PHTNa. & .027 \\
\hline Need for HFOV ${ }^{b}$ and duration & 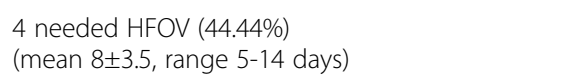 & $\begin{array}{l}5 \text { needed HFOV ( } 83.33 \%) \\
\text { (mean 2.2 } \pm 2.4 \text {, range } 1-7 \text { days) }\end{array}$ & .286 \\
\hline
\end{tabular}

${ }^{a}$ Severe pulmonary hypertension (PHTN): estimated pulmonary arterial pressure that is equal to systemic blood pressure or more (suprasystemic) 
Table 2 Spectrum of congenital heart disease (CHD), degree of pulmonary hypertension (PHTN), and patient outcome

\begin{tabular}{|c|c|c|}
\hline $\begin{array}{l}\text { Infant } \\
\text { details }\end{array}$ & Type of CHD and degree of PHTN & Outcome \\
\hline Infant 1 & $\begin{array}{l}\text {-Left pulmonary artery stenosis, PDA } \\
\text {-Mild pulmonary hypertension }\end{array}$ & Survived \\
\hline Infant 2 & $\begin{array}{l}\text {-Small muscular VSD, moderately dilated right ventricle } \\
\text {-Moderate to severe pulmonary hypertension }\end{array}$ & Survived \\
\hline Infant 3 & $\begin{array}{l}\text {-Small ASD, moderate PDA } \\
\text {-Mild pulmonary hypertension }\end{array}$ & Survived \\
\hline Infant 4 & $\begin{array}{l}\text {-Mild tricuspid regurgitation, large PDA, PFO, mild dilated right atrium } \\
\text {-Moderate to severe pulmonary hypertension }\end{array}$ & Survived \\
\hline Infant 5 & $\begin{array}{l}\text { PDA, small PFO, mild tricuspid regurgitation } \\
\text {-Moderate to severe pulmonary hypertension }\end{array}$ & Survived \\
\hline Infant 6 & $\begin{array}{l}\text {-Severe pulmonary artery stenosis, PDA, PFO, VSD, double outlet right ventricle, right aortic } \\
\text { arch } \\
\text {-Severe pulmonary hypertension }\end{array}$ & Died (at age of 9 months) \\
\hline Infant 7 & $\begin{array}{l}\text {-ASD } \\
\text {-Severe pulmonary hypertension }\end{array}$ & Died (at age of 1 day) \\
\hline Infant 8 & $\begin{array}{l}\text {-ASD } \\
\text {-Severe pulmonary hypertension }\end{array}$ & Died (at age of 1 day) \\
\hline Infant 9 & $\begin{array}{l}\text {-ASD, dilated right ventricle and atrium, large PDA } \\
\text {-Severe pulmonary hypertension }\end{array}$ & Died (at age of 1 day) \\
\hline Infant 10 & $\begin{array}{l}\text {-Right sided aortic arch, moderate PDA, moderate tricuspid regurgitation } \\
\text {-Severe pulmonary hypertension }\end{array}$ & $\begin{array}{l}\text { Died (preoperatively at age of } 22 \\
\text { days) }\end{array}$ \\
\hline
\end{tabular}

PDA patent ductus arteriosus, ASD atrial septal defect, PFO patent foramen ovale, VSD ventricular septal defect

Early prenatal diagnosis is important, as the mother should be referred to a tertiary care center for optimal care before birth. Most $\mathrm{CDH}$ defects are detected after 16 weeks of gestation. The prenatal detection rate varies in published studies, from 50 to $70 \%$ [17]. However, prenatal detection of $\mathrm{CDH}$ is uncommon in developing countries due to inadequate facilities and poor patient compliance [12]. In our study, 6/15 (40\%) of the cases were diagnosed prenatally as RB-CDH. Threedimensional estimation of the total fetal lung volume (TFLV), calculation of lung to head ratio (LHR), observed to expected lung head ratio (O/E LHR), and calculation of the lung to thoracic circumference ratio have been widely used as prognostic indicators $[18,19]$. This study's limitation is the unavailability of the antenatal ultrasonographic measurements (LHR and TFLV) in the medical records.

Ramakrishnan and colleagues found that isolated $\mathrm{CDH}$ cases had better neonatal and 1-year survival rates, and chromosomal cases were associated with the worst survival rates [20]. Cardiac malformations are the most common associated anomalies. In a review of 4268 infants with $\mathrm{CDH}$, approximately $18 \%$ of infants had an associated cardiac defect. Major cardiac lesions (excluding PFO, ASD, PDA) were associated with overall survival of $36 \%$ compared to infants with minor anomalies $(67 \%$ survival) and those without cardiac defects (73\% survival) [21]. In our review, none of the neonates had associated syndromes. Among the nonlethal cardiac malformations, ASD, VSD, and PFO predominated, similar to the findings reported by Sweed $\mathrm{Y}$ and colleagues [22].

Identification and management of pulmonary hypertension are critically important in the newborn period. $\mathrm{CDH}$-associated pulmonary hypertension was gradedby echocardiography-into mild, moderate, and severe based on pressure gradient through ductus arteriosus. In our study, all non-survivors had signs of severe PHTN, whereas 3 out of 9 survivors (33.33\%) had moderate to severe PHTN, with a $P$ value of .027 , which was statistically significant.

The concept of gentle ventilation strategies (permissive hypercapnia) was introduced by Wung and colleagues in their 1995 retrospective, nonrandomized study to reduce iatrogenic lung injury from barotrauma; this ventilation strategy has been employed in most centers, including our center [23]. HFOV has also been utilized in the perinatal management of $\mathrm{CDH}$ to reduce pulmonary barotraumas. In this study, all patients received mechanical ventilation. Four out of nine (44.44\%) survivors and 5/6 (83.33\%) non-survivors received HFOV, with a $P$ value of .286, which was statistically insignificant. HFOV was used for patients with refractory hypercapnia or high peak inspiratory pressures, and only one neonate required it postoperatively. HFOV may be a more effective mode of ventilatory support than conventional ventilation when used as an initial mode of therapy [24]. Extracorporeal membrane oxygenation (ECMO) is used if 
HFOV fails to maintain the goal physiologic parameters. Inhaled nitric oxide (iNO) was initiated at $20 \mathrm{ppm}$ for all patients receiving HFOV. Usui et al. reported 14\% incidence of pneumothorax among 510 neonates with $\mathrm{CDH}$ [25]. In our study, none of the neonates who had pneumothorax survived.

Delayed surgical repair is the current management in most of the surgical centers. Preoperative stabilization aims at optimizing the respiratory function and allowing full clinical and cardiac assessment. We operated on 11 RB-CDH cases via an upper transverse or subcostal abdominal incision. We used polypropylene mesh in one patient which had a big defect size. Unfortunately, he did not survive. Minimally invasive approach has the advantage of decreased postoperative pain; however, the recurrence rate appears to be higher than with open techniques, and the patient should have stringent intraoperative monitoring of ETCO2 and PaCO2 [15].

The presence of hernia sac with $\mathrm{CDH}$ - which was reported in $20 \%$ of patients-can improve the prognosis in affected neonates [26]. Intraoperatively, we found a hernia sac in 5/11 (45.5\%) neonates; all of them survived.

Liver herniation into the chest is considered a poor prognostic sign. Fibrous fusion between the liver and the lung has been reported [27]. We observed hepatopulmonary fusion in one patient which required thoracotomy in addition to right subcostal incision. These anatomic findings can significantly complicate the diaphragmatic defect repair.

Recurrent diaphragmatic hernia is a dominant surgical challenge. The reported recurrence rate is $15 \%$ in the first couple of years following repair. One CDHSG registry review found that large hernial defect and the use of a minimally invasive surgery were associated with early recurrence after $\mathrm{CDH}$ repair [28]. Recurrent hernias may occur in up to $28 \%$ of infants undergoing mesh repairs and in $2 \%$ of primary repairs [29]. In our study, we encountered one patient with recurrent hernia who presented with vomiting at 40 days old and 9 months of age, which was successfully repaired and is doing well in 3 years follow-up.

The overall survival rate of $\mathrm{CDH}$ neonates in NICU ranges from 21 to $83 \%$ according to various recent studies [30]. Multiple studies from developing countries reported $50 \%-65 \%$ rate of survival for $\mathrm{CDH}$ patients [31]. Recent studies from developed countries have shown improved survival rate for isolated $\mathrm{CDH}$ up to $85 \%-90 \%$ [32].

Several studies have shown that RB-CDH is associated with higher mortality than LB-CDH $[33,34]$. Burgos and colleagues explained that by the higher proportion of larger defects in this group compared to LB-CDH. Therefore, it seems that the hernial defect size is important for the outcome of $\mathrm{CDH}$ [35]. However, other reports did not find a statistical difference in mortality rate when compared to left-sided defects [36, 37]. A recently published French national cohort study found that patients with RB-CDH did not have a higher risk of mortality than LB-CDH [38]. Another retrospective multicenter study compared characteristics and outcomes of neonates with RB-CDH vs. LB-CDH and found no difference in mortality or hernia recurrence [39].

In a study by Aihole and colleagues, a quarter of neonates $(25 \%)$ with RB-CDH died preoperatively [40]. In our study, 4/15 (27\%) of RB-CDH neonates did not survive to the time of surgical repair, and 2 died post repair while $9 / 11$ (82\%) of neonates survived postoperatively with total mortality of $40 \%$ (4 preop and 2 postop). Interestingly, Thomas et al. found infants with RB-CDH had a better survival than those with LB-CDH [41].

\section{Conclusion}

We found that low birth weight and the presence of severe PHTN were risk factors for mortality in neonates with RB-CDH. These results are in line with previous studies on prognostic factors in $\mathrm{CDH}$. Ventilator-related pneumothorax appears to be a significant contributing cause of death. Long-term follow-up studies of infants born with RB-CDH are needed as large-volume RB$\mathrm{CDH}$ studies are limited by small numbers of cases.

\section{Abbreviations}

$\mathrm{CDH}$ : Congenital diaphragmatic hernia; RB-CDH: Right Bochdaleck congenital diaphragmatic hernia; LB-CDH: Left Bochdaleck congenital diaphragmatic

hernia; PHTN: Pulmonary hypertension; CT scans: Computerized tomography scans; DM: Diabetes mellitus; VSD: Ventricular septal defect;

PTFE: Polytetrafluoroethylene; GERD: Gastroesophageal reflux disease; PPHN: Persistent pulmonary hypertension of the newborn; HFOV: High frequency oscillatory ventilation; ECMO: Extracorporeal membrane oxygenation; TFLV: Total fetal lung volume; LHR: Lung to head ratio; O/E LHR: Observed to expected lung head ratio; PFO: Patent foramen ovale; ASD: Atrial septal defect; PDA: Patent ductus arteriosus; iNO: Inhaled nitric oxide; ETCO2: End-tidal CO2; PaCO2: Partial pressure of carbon dioxide; CDHSG: Congenital diaphragmatic hernia study group; NICU: Neonatal intensive care unit

\section{Acknowledgements}

Not applicable

\section{Authors' contributions}

Dr. AA designed the study, collected patients' data, analyzed, and interpreted patients' data. Dr. ER performed the final drafting and critical revision and was a major contributor in writing the manuscript. All authors read and approved the final manuscript. All authors attest that they meet the current ICMJE criteria for authorship.

\section{Funding}

No funding or grant support.

\section{Availability of data and materials}

The datasets used and/or analyzed during the current study are available from the corresponding author on reasonable request.

\section{Ethics approval and consent to participate}

This study was conducted in accordance with the Declaration of Helsinki and approved by the research and ethics committee of King Fahd Armed Forces Hospital (reference number is not available). Consent to publish this 
study was not obtained. This study does not contain any personal information that could lead to the identification of the patient.

\section{Consent for publication}

Not applicable

\section{Competing interests}

The authors report no competing interests.

Received: 25 August 2020 Accepted: 15 February 2021

Published online: 05 May 2021

\section{References}

1. McGivern MR, Best KE, Rankin J, et al. Epidemiology of congenital diaphragmatic hernia in Europe: a register-based study. Arch Dis Child Fetal Neonatal. 2015;100:F137-44.

2. Parker SE, Mai CT, Canfield MA, Rickard R, Wang Y, Meyer RE, et al. Updated national birth prevalence estimates for selected birth defects in the United States,2004-2006. Birth Defects Res A Clin Mol Teratol. 2010;88(12):1008-16. https://doi.org/10.1002/bdra.20735.

3. Kluth $D$, Keijzer R, Hertl M, et al. Embryology of congenital diaphragmatic hernia. Semin Pediatr Surg. 1996;5:224-33.

4. Torfs CP, Curry CJ, Bateson TF, et al. A population-based study of congenital diaphragmatic hernia. Teratology. 1992;46:555-65.

5. Keller RL, Tacy TA, Hendricks-Munoz K, et al. Congenital diaphragmatic hernia: endothelin-1, pulmonary hypertension, and disease severity. Am J Respir Crit Care Med. 2010;182(4):555-61.

6. Kilian AK, Schaible T, Hofmann V, et al. Congenital diaphragmatic hernia: predictive value of MRI relative lung-to-head ratio compared with MRI fetal lung volume and sonographic lung-to-head ratio. AJR Am J Roentgenol. 2009:192:153-8

7. Muratore CS, Wilson JM. Congenital diaphragmatic hernia: where are we and where do we go from here? Semin Perinatol. 2000;24:418-28.

8. Gallot D, Boda C, Ughetto S, et al. Prenatal detection and outcome of congenital diaphragmatic hernia: a French Registry-based study. Ultrasound Obstet Gynecol. 2007;29:276-83.

9. Balayla J, Abenhaim HA. Incidence, predictors and outcomes of congenital diaphragmatic hernia: a population-based study of 32 million births in the United States. The Journal of Maternal-Fetal \& Neonatal Medicine. 2014; 27(14):1438-44. https://doi.org/10.3109/14767058.2013.858691.

10. Cohen-Katan S, Newman-Heiman N, Staretz-Chacham O, Cohen Z, Neumann L, Shany E, et al. Congenital diaphragmatic hernia: short-term outcome. Isr Med Assoc J. 2009;11:219-24.

11. Harrison MR, Bjordal RI, Langmark F, Knutrud O. Congenital diaphragmatic hernia: the hidden mortality. J Pediatr Surg. 1978;13:227-30.

12. Poondla VR, Kothakoona S, Rao KV, Kameswari K. Study of atypical presentations in congenital diaphragmatic hernia. J Evol Med Dent Sci. 2015;4:14476-9.

13. Dott MM, Wong L-YC, Rasmussen SA. Population-based study of congenital diaphragmatic hernia: risk factors and survival in metropolitan Atlanta, 1968-1999. Birth Defects Research Part A: Clinical and Molecular Teratology. 2003;67(4):261-7. https://doi.org/10.1002/bdra.10039.

14. Tsao K, Allison ND, Harting MT, Lally PA, Lally KP. Congenital diaphragmatic hernia in the preterm infant. Surgery. 2010;148(2):404-10. https://doi.org/1 0.1016/j.surg.2010.03.018

15. Grover TR, Murthy K, Brozanski B, Gien J, Rintoul N, Keene S, et al. Shortterm outcomes and medical and surgical interventions in infants with congenital diaphragmatic hernia. Am J Perinatol. 2015;32:1038-44.

16. Holcomb G, Murphy J, St. Peter S, Gatti J. Holcomb and Ashcraft's pediatric surgery. 6th ed; 2010. p. 317-22.

17. Dillon E, Renwick M, Wright C. Congenital diaphragmatic herniation: antenatal detection and outcome. Br J Radiol. 2000;73:360-5.

18. Ruano R, Benachi A, Martinovic J, et al. Can three-dimensional ultrasound be used for the assessment of the fetal lung volume in cases of congenital diaphragmatic hernia? Fetal Diagn Ther. 2004;19:87-91.

19. DeVore GR, Horenstein J, Platt LD. Fetal echocardiography. VI. Assessment of cardiothoracic disproportion-a new technique for the diagnosis of thoracic hypoplasia. Am J Obstet Gynecol. 1986;155:1066-71.

20. Ramakrishnan R, Salemi JL, Stuart AL, et al. Trends, correlates, and survival of infants with congenital diaphragmatic hernia and its subtypes. Birth Defects Research. 2018:1-11. https://doi.org/10.1002/bdr2.1357.
21. Menon SC, Tani LY, Weng HY, et al. Clinical characteristics and outcomes of patients with cardiac defects and congenital diaphragmatic hernia. J Pediatr. 2013;162:114-9.

22. Sweed Y, Puri P. Congenital diaphragmatic hernia: influence of associated malformations on survival. Arch Dis Child. 1993;69:68-70.

23. Wung JT, Sahni R, Moffitt ST, Lipsitz E, Stolar CJ. Congenital diaphragmatic hernia: survival treated with very delayed surgery, spontaneous respiration, and no chest tube. J Pediatr Surg. 1995;30:406-9.

24. Boix-Ochoa J, Peguero G, Seijo G, Natal A, Canals J. Acid-base balance and blood gases in prognosis and therapy of congenital diaphragmatic hernia. Pediatr Surg. 1974:9:49-57.

25. Usui N, Okuyama H, Sawai T, Kamiyama M, Kamata S, Fukuzawa M, et al. Relationship between $\mathrm{L} / \mathrm{T}$ ratio and LHR in the prenatal assessment of pulmonary hypoplasia in congenital diaphragmatic hernia. Pediatr Surg Int. 2007;23:971-6

26. Panda SS, Bajpai M, Srinivas M. Presence of hernia sac in prediction of postoperative outcome in congenital diaphragmatic hernia. Indian Pediatr. 2013;50:1041-3.

27. Almaramhy HH. Hepatopulmonary fusion associated with right-sided congenital diaphragmatic hernia: management of this rare anomaly and a review of the literature. J Int Med Res, 030006051875989. 2018. https://doi. org/10.1177/0300060518759892.

28. Putnam LR, Gupta V, Tsao K, et al. Factors associated with early recurrence after congenital diaphragmatic hernia repair. J PediatrSurg. 2017;52:928-32.

29. Mitchell IC, Garcia NM, Barber R, et al. Permacol: a potential biologic patch alternative in congenital diaphragmatic hernia repair. J Pediatr Surg. 2008; 43:2161-4.

30. Bagolan P, Casaccia G, Crescenzi F, Nahom A, Trucchi A, Giorlandino C, et al. Impact of a current treatment protocol on outcome of high-risk congenital diaphragmatic hernia. J Pediatr Surg. 2004;39:313-8.

31. Jain A, Singh V, Sharma M. Congenital diaphragmatic hernia: our experience - a brief review. Indian J Anaesth. 2002;46:426-9.

32. Ontario Congenital Anomalies Study Group. Apparent truth about congenital diaphragmatic hernia: a population-based database is needed to establish benchmarking for clinical outcomes for CDH. J Pediatr Surg. 2004; 39:661-5.

33. Skari $H$, Bjornland $K$, Haugen $G$, et al. Congenital diaphragmatic hernia: a metaanalysis of mortality factors. J Pediatr Surg. 2000;35:1187-97.

34. Fisher JC, Jefferson RA, Arkovitz MS, et al. Redefining outcomes in right congenital diaphragmatic hernia. J Pediatr Surg. 2008;43:373-9.

35. Burgos CM, Frenckner B, Luco M, Harting MT, Lally PA, Lally KP. Right versus left congenital diaphragmatic hernia - what's the difference? Journal of Pediatric Surgery. 2018;53(1):113-7. https://doi.org/10.1016/j.jpedsurg.2017.1 0.027 .

36. Stege G, Fenton A, Jaffray B. Nihilism in the 1990s: the true mortality of congenital diaphragmatic hernia. Pediatrics. 2003;112:532-5.

37. Wilson JM, Lund DP, Lillehei CW, et al. Congenital diaphragmatic hernia-a tale of two cities: the Boston experience. J Pediatr Surg. 1997;32:401-5.

38. Pinton A, Boubnova J, Becmeur F, Kuhn P, Senat M-V, Stirnemann J, et al. Is laterality of congenital diaphragmatic hernia a reliable prognostic factor? French national cohort study. Prenatal Diagnosis. 2020. https://doi.org/10.1 002/pd.5706.

39. Abramov A, Fan W, Hernan R, Zenilman AL, Wynn J, Aspelund G, et al. Comparative outcomes of right versus left congenital diaphragmatic hernia: a multicenter analysis. J Pediatr Surg. 2019. https://doi.org/10.1016/j. jpedsurg.2019.09.046.

40. Aihole JS, Gowdra A, Javaregowda D, Jadhav V, Babu MN, Sahadev R. A clinical study on congenital diaphragmatic hernia in neonates: our institutional experience. J Indian Assoc Pediatr Surg. 2018;23(3):131-9. https://doi.org/10.4103/jiaps.JIAPS_179_17.

41. Schaible T, Kohl T, Reinshagen K, Brade J, Neff KW, Stressig R, Büsing KA. Right- versus left-sided congenital diaphragmatic hernia. Pediatric Critical Care Medicine. 2012;13(1):66-71.

\section{Publisher's Note}

Springer Nature remains neutral with regard to jurisdictional claims in published maps and institutional affiliations. 